\title{
A Meta-Analysis of Pedometer-Based Walking Interventions and Weight Loss
}

\author{
Caroline R. Richardson, $M D^{1,2}$ \\ Tiffany L. Newton, BS ${ }^{1}$ \\ Jobby J. Abrabam, MBBS ${ }^{1}$ \\ Ananda Sen, $P b D^{3}$ \\ Masabito Jimbo, $M D, P b D, M P H^{1}$ \\ Ann M. Swartz, $P b D^{4}$ \\ 'Department of Family Medicine, \\ University of Michigan Medical School, \\ Ann Arbor \\ ${ }^{2}$ Health Services Research and Develop- \\ ment Center, Ann Arbor Veterans' Affairs \\ Medical Center, Ann Arbor, Michigan \\ ${ }^{3}$ Center for Statistical Consultation and \\ Research (CSCAR) and Department of Sta- \\ tistics, University of Michigan, Ann Arbor \\ ${ }^{4}$ Department of Human Movement \\ Sciences, University of Wisconsin - \\ Milwaukee, College of Health Sciences, \\ Milwaukee
}

AC Annals Journal Club selection; see inside back cover or http://www. annfammed.org/AJC/.

Conflicts of interest: none reported

\section{CORRESPONDING AUTHOR}

Caroline R. Richardson, MD Department of Family Medicine University of Michigan 1018 Fuller St

Ann Arbor, MI 48104

caroli@umich.edu

\begin{abstract}
PURPOSE Cross-sectional studies show that individuals who walk more tend to be thinner than those who walk less. This does not mean, however, that the association between higher step counts and lower weight is causal or that encouraging sedentary individuals to increase step counts helps them lose weight.
\end{abstract}

METHODS In this meta-analysis, we searched 6 electronic databases and contacted pedometer experts to identify pedometer-based walking studies without a dietary intervention that reported weight change as an outcome. We included randomized controlled trials and prospective cohort studies published after January 1, 1995, in either English or Japanese, with 5 or more adult participants and at least 1 cohort enrolled in a pedometer-based walking intervention lasting at least 4 weeks.

RESULTS Nine studies met the study inclusion criteria. Cohort sample size ranged from 15 to 106, for a total of 307 participants, $73 \%$ of whom were women and $27 \%$ of whom were men. The duration of the intervention ranged from 4 weeks to 1 year, with a median duration of 16 weeks. The pooled estimate of mean weight change from baseline using a fixed-effects model and combining data from all 9 cohorts was $-1.27 \mathrm{~kg}$ ( $95 \%$ confidence interval, -1.85 to $-0.70 \mathrm{~kg}$ ). Longer intervention duration was associated with greater weight change. On average, participants lost $0.05 \mathrm{~kg}$ per week during the interventions.

CONCLUSION Pedometer-based walking programs result in a modest amount of weight loss. Longer programs lead to more weight loss than shorter programs.

Ann Fam Med 2008;6:69-77. DOI: 10.1370/afm.761.

\section{INTRODUCTION}

$\mathrm{O}$ besity is increasing in prevalence among adults in the United States at an alarming rate. ${ }^{1}$ The prevalences of type 2 diabetes ${ }^{2,3}$ and other obesity-related chronic illnesses are increasing along with the prevalence of obesity. Both obesity and type 2 diabetes are preventable with diet and exercise modifications. ${ }^{4}$

Cross-sectional observational studies have shown that people who walk more tend to be thinner than those who walk less. ${ }^{5.9}$ In a typical pedometer-based walking intervention, participants are given a pedometer to wear every day, all day, as they go about their usual activities. Pedometers are small, inexpensive devices about the size of a pager that are worn at the waist and that count every step the wearer takes during the day. Participants are also given an assigned or negotiated total daily step-count goal. Pedometer-based walking programs show promise as an adjunct both in dietary weight loss interventions ${ }^{10}$ and in preventing weight regain after substantial weight loss. ${ }^{8,11}$

Most simple pedometers only provide feedback on total daily steps taken, feedback on intensity, duration, or frequency of walking is not provided. In contrast to walking programs that use time-based walking goals, pedometer-based walking programs make it possible to meet a relatively high step-count goal either by going for 1 long walk or by taking 
lots of very short walks spread throughout the day. It is in part the flexibility to fit in walking whenever it is convenient for the individual participant that makes pedometer-based walking programs popular. At the same time, the flexibility also adds some uncertainty with respect to the health benefits of pedometer-based walking programs. The amount of weight loss that a sedentary adult can expect to achieve from these programs in the absence of dietary modification or other nonexercise interventions is not known.

In this meta-analysis, we examined the effects of pedometer-based walking interventions on weight loss. We included in the analysis studies of walking programs without dietary intervention that used pedometers as motivational tools and that were conducted among overweight or obese, sedentary adults.

\section{METHODS}

\section{Study Design and Primary Outcome}

This study was a meta-analysis with a quantitative synthesis of the literature examining weight loss in overweight or obese, sedentary participants in pedometerbased walking programs. The primary outcome was the change in weight calculated as within-participant weight loss in a preintervention-postintervention analysis.

\section{Inclusion Criteria}

We included in the quantitative synthesis studies that met the following criteria:

1. The study was an intervention study using pedometers as motivational tools to increase walking, including step-count goal setting and continuous self-monitoring.

2. The study was either a controlled trial (whether randomized or not) or a preintervention and postintervention prospective cohort study.

3. The study was published (whether as a complete manuscript, a brief report, or an abstract alone), and the report had sufficient detail to confirm that the study met other meta-analysis inclusion criteria.

4. The study did not include any concurrent dietary intervention.

5. Preintervention and postintervention mean weights were reported or could be easily calculated for the intervention group.

6. The study had at least 5 participants.

7. Participants were adults who were sedentary at baseline.

8. Participants were overweight or obese (study average body mass index $>25 \mathrm{~kg} / \mathrm{m}^{2}$ ).

9. The intervention lasted at least 4 weeks.

10. The study was reported in English or Japanese.

11. The study was published after January 1, 1995, when accurate and inexpensive pedometers became readily available.

\section{Study Identification}

We used 2 different methods to identify studies to include in this meta-analysis. First, 2 of the authors (C.R.R., T.L.N.) conducted a systematic search of 6 databases for citations related to walking or pedometers. The databases searched were CINAHL, EMBASE, MEDLINE, PsycINFO, SportDiscus, and Web of Science. The search was conducted on July 8, 2005, using search terms that included "walking," "pedometer," "step count," and "sedentary." An updated search was conducted on September 12, 2006, using CINAHL, MEDLINE, PsycINFO, SportDiscus, and Web of Science; EMBASE was no longer accessible from our institution. Once the search was completed 1 author (T.L.N.) reviewed abstracts to screen out papers that clearly did not meet the inclusion criteria. Several authors (T.L.N., C.R.R., J.J.A.) reviewed in more detail studies that could not be excluded based on the abstract alone or studies without abstracts to determine if they met our inclusion criteria.

Additionally, we contacted experts in the pedometer research field to find other studies that might be eligible for inclusion. Some of the studies identified by the experts that did meet inclusion criteria were published after the date of the automated database search.

\section{Quality Assessment}

Because our analysis focused on preintervention-postintervention weight change, we were able to include both controlled and uncontrolled trials. To rate study quality, we used a modified version of the Downs and Black quality-scoring system. ${ }^{12}$ Items rated in the quality-scoring system included sample size, sample selection, outcome assessment quality, rate of dropout, quality of the statistical analysis, adjustment for confounding, and reporting details. Because blinding is not possible in an intervention based on self-monitoring and because the analysis was based on preinterventionpostintervention comparisons rather than a comparison between randomized groups, we omitted items in the quality scale related to randomization and blinding. Two raters (C.R.R., J.J.A.) rated all included studies, and discrepancies were resolved by consensus.

\section{Data Analysis}

To ascertain within-participant weight change from preintervention assessment to postintervention assessment, we either obtained it directly from the study results or calculated it by determining the difference between reported mean weights before and after the intervention. All weights were converted to kilogram units. All 
statistics were computed using STATA 9.0 (StataCorp LP, College Station, Texas, 2005) and MINITAB 14.0 (Minitab Inc, State College, Pennsylvania, 2004).

\section{Standard Deviations}

To conduct a meta-analysis, one must have a standard deviation of the outcome being measured in each study. This value allows for calculation of the effect size for each study. Many of the included studies did not report the standard deviation of the change in weight but instead reported the standard deviation for the preintervention and postintervention weights. For those studies that reported exact $P$ values for the preinterventionpostintervention comparison, we could easily derive the standard deviation of the change in weight. For studies without exact $P$ values, or $t$ statistics, we imputed the standard deviation of the change using the individual preintervention and postintervention standard deviations as well as the within-participant correlation of the weight measures, with the formula displayed in Figure 1.

In using this strategy, we made the assumption that the correlation of within-participant preintervention and postintervention weights was similar across studies. This assumption allowed us to estimate effect sizes for all of the cohorts included in the analysis. The strategy we adopted is similar to that recommended by Follmann et al. ${ }^{13}$

We used a within-participant correlation of 0.98 for studies that had an intervention duration of less than 3 months (12 weeks) and 0.95 for studies that had an intervention duration of 3 to 9 months (12-36 weeks). These correlation values were computed exactly for a few studies and were assumed to hold for the studies that were similar in duration.

\section{Publication Bias and Heterogeneity}

To test for evidence of publication bias, we examined a standard funnel plot. ${ }^{14}$ A funnel plot is simply a scatterplot of the measure of interest against the reciprocal of the corresponding standard error. Publication bias refers to the preferential publication of only those studies with significant results. Nonsignificant results would typically be accompanied by larger variability and vice versa. A lack of publication bias would thus be indicated by a rough inverted funnel shape of the above plot, thereby showing the presence of both significant and nonsignificant results in the data. In addition to this graphical check for bias, we also used the rank-correlation test of Begg and Mazumdar ${ }^{15}$ and the test of Egger et al, ${ }^{16}$ both of which are formal statistical tests of bias that are based on the same consideration underlying the funnel plot.

To test for heterogeneity between studies in the analysis, we used the Cochran $Q$ statistic, ${ }^{17}$ which is simply the sum of squared deviations of the studyspecific estimates from the overall pooled estimate, weighting each study's contribution in the same manner as in the meta-analysis. $P$ values were obtained by comparing the statistic $Q$ with a $\chi^{2}$ distribution with $k-1$ degrees of freedom, where $k$ is the number of studies considered.

\section{Effect Sizes}

Because the Cochran test demonstrated heterogeneity, we used a random-effects model to calculate the pooled estimate of mean weight change from baseline, combining data from all cohorts, and generated a forest plot to illustrate both the study-specific effect sizes (along with an associated 95\% confidence interval) and the pooled effect estimate based on this model. The weights used in combining estimates equal the reciprocal of the sum of 2 variances: (1) the estimated variance associated with the study and (2) the estimated component of variance due to variation between studies. To further test the overall significance based on a more general method of combining $P$ values, we calculated the Fisher log-likelihood ratio statistic and the associated $P$ value for the statistic using a $\chi^{2}$ test with twice the total number of studies for degrees of freedom.

\section{Meta-Regression Model}

We used a mixed-effects meta-regression model to assess whether there was any association of study duration and quality scores with the weight change effect size. Both duration of intervention and quality scores were entered in the model as fixed effects, and study was considered as a random effect.

\section{RESULTS}

\section{Study Identification}

After compiling search results across all databases and eliminating duplicates, we found 1,405 articles that were published between January 1, 1995, and September 12, 2006, that were about pedometers or walking. By reviewing the abstracts for these 1,405 articles to exclude articles that were not intervention trials involving pedometer-based walking programs, we identified 86 studies for more extensive review and inclusion criteria screening. Of these 86 studies reviewed in detail, 9 met our

inclusion criteria.

\section{Figure 1.}

SDchange $=\sqrt{\left(S D_{\text {pre }}\right)^{2}+\left(S D_{\text {post }}\right)^{2}-2 \times \text { corr }(\text { pre, post }) \times S D_{\text {pre }} \times S D_{\text {post }}}$ 


\begin{tabular}{|c|c|c|c|c|c|}
\hline Study (Year) & $\begin{array}{l}\text { No. of } \\
\text { Participants } \\
\text { (Study Design) }\end{array}$ & Population & $\begin{array}{l}\text { Dropout } \\
\text { No. (\%) }\end{array}$ & $\begin{array}{l}\text { Weight-Related } \\
\text { Inclusion Criteria }\end{array}$ & $\begin{array}{l}\text { Baseline BMI } \\
\text { Mean } \pm \text { SD } \\
\text { (Range), kg/m² }\end{array}$ \\
\hline $\begin{array}{l}\text { Engel and Lindner }{ }^{18} \\
\text { (2006) }\end{array}$ & $\begin{array}{c}22 \\
(\mathrm{RCT})\end{array}$ & $\begin{array}{l}\text { Sedentary men and women with } \\
\text { type } 2 \text { diabetes with a mean age } \\
\text { of } 60.5 \text { years }\end{array}$ & $2(8)$ & None & $32.7 \pm 5.5$ \\
\hline $\begin{array}{l}\text { Wilson et al }{ }^{19} \\
(2005)\end{array}$ & $\begin{array}{l}22 \\
\text { (Cohort) }\end{array}$ & $\begin{array}{l}\text { African American breast cancer } \\
\text { survivors with a mean age of } \\
55 \text { years }\end{array}$ & $2(8)$ & None & $\begin{array}{c}32.7 \\
(25.2-47.2)\end{array}$ \\
\hline $\begin{array}{l}\text { Miyatake et al20 } \\
(2002)\end{array}$ & $\begin{array}{l}31 \\
\text { (Cohort) }\end{array}$ & Japanese men aged 32 to 59 years & $\begin{array}{l}\text { Not } \\
\text { reported }\end{array}$ & $\mathrm{BMI}>25 \mathrm{~kg} / \mathrm{m}^{2}$ & $28.6 \pm 2.2$ \\
\hline $\begin{array}{l}\text { Schneider et } \mathrm{al}^{21} \\
(2006)\end{array}$ & $\begin{array}{l}38 \\
\text { (Cohort) }\end{array}$ & $\begin{array}{l}\text { Sedentary overweight or obese } \\
\text { but otherwise healthy adults } \\
\text { aged } 30 \text { to } 60 \text { years }\end{array}$ & $18(32)$ & $\mathrm{BMI}>25 \mathrm{~kg} / \mathrm{m}^{2}$ & $33.5 \pm 5.0$ \\
\hline $\begin{array}{l}\text { Tudor- Locke et al } 22 \\
\text { (2004) }\end{array}$ & $\begin{array}{c}24 \\
(\mathrm{RCT})\end{array}$ & $\begin{array}{l}\text { Overweight or obese, sedentary } \\
\text { individuals with type } 2 \text { diabetes } \\
\text { and a mean age of } 52.7 \text { years }\end{array}$ & $6(20)$ & None & $34.1 \pm 6.1$ \\
\hline $\begin{array}{l}\text { Swartz et al }{ }^{23} \\
(2003)\end{array}$ & $\begin{array}{c}18 \\
\text { (Cohort) }\end{array}$ & $\begin{array}{l}\text { Overweight or obese women with } \\
\text { family history of type } 2 \text { diabetes }\end{array}$ & $1(5)$ & $\mathrm{BMI}>25 \mathrm{~kg} / \mathrm{m}^{2}$ & $35.0 \pm 5.1$ \\
\hline $\begin{array}{l}\text { Moreau et a }\left.\right|^{24} \\
\text { (2001) }\end{array}$ & $\begin{array}{c}15 \\
(\mathrm{RCT})\end{array}$ & $\begin{array}{l}\text { Sedentary, postmenopausal } \\
\text { women with stage } 1 \text { hyperten- } \\
\text { sion and a mean age of } 54 \text { years }\end{array}$ & $\begin{array}{l}\text { Not } \\
\text { reported }\end{array}$ & None & $>25^{b}$ \\
\hline $\begin{array}{l}\text { Hultquist et al } \\
\text { (2005) }\end{array}$ & $\begin{array}{c}31 \\
(\mathrm{RCT})\end{array}$ & $\begin{array}{l}\text { Sedentary, healthy, nonsmoking } \\
\text { women aged } 33 \text { to } 55 \text { years }\end{array}$ & $0(0)$ & $\mathrm{BMI}<40 \mathrm{~kg} / \mathrm{m}^{2}$ & $30 \pm 6.4$ \\
\hline $\begin{array}{l}\text { Chan et al }{ }^{26} \\
(2004)\end{array}$ & $\begin{array}{c}106 \\
\text { (Cohort) }\end{array}$ & $\begin{array}{l}\text { Sedentary workers with a mean } \\
\text { age of } 43 \text { years }\end{array}$ & $71(40)$ & None & $29.5 \pm 5.9$ \\
\hline
\end{tabular}

$\mathrm{BMI}=$ body mass index; $\mathrm{RCT}=$ randomized controlled trial.

a Number represents only study completers and, for RCTs, only participants randomized to the pedometer intervention arm of the study.

${ }^{\mathrm{b}}$ Calculation was based on other data in the report.

Table 2. Step Count and Weight Change Data From Studies That Met Inclusion Criteria

\begin{tabular}{|c|c|c|c|c|c|c|}
\hline \multirow[b]{2}{*}{ Study (Year) } & \multicolumn{3}{|c|}{ Step Count } & \multicolumn{3}{|c|}{ Weight, kg } \\
\hline & Preintervention & Postintervention & Change & Preintervention & Postintervention & Change \\
\hline Engel and Lindner ${ }^{18}$ (2006) & NR & $7,296 \pm 2,066$ & NR & $91.9 \pm 18.4$ & $89.8^{a}$ & $-2.1^{\mathrm{a}}$ \\
\hline Wilson et al ${ }^{19}$ (2005) & 4,791 & $8,297^{a}$ & 3,506 & 86.7 & 85.8 & $-0.9^{b}$ \\
\hline Miyatake et al'20 (2002) & $7,013 \pm 3,077$ & $8,840 \pm 4,342$ & 1,827 & $82.3 \pm 7.4$ & $78.6 \pm 7.4$ & $-3.7^{b}$ \\
\hline Schneider et al ${ }^{21}$ (2006) & $5,123 \pm 1,271$ & $9,117 \pm 1,697$ & 3,994 & $98.8 \pm 18.6$ & $96.4 \pm 17.8$ & $-2.4^{b}$ \\
\hline Tudor-Locke et al22 (2004) & $5,753^{a}$ & $9,123 \pm 4,539$ & 3,370 & $96.8 \pm 23.9$ & $96.1 \pm 22.8$ & -0.7 \\
\hline Swartz et $\mathrm{al}^{23}$ (2003) & $4,972 \pm 419$ & $9,213 \pm 362^{c}$ & 4,241 & $94.0 \pm 3.6$ & $94.3 \pm 3.4^{c}$ & +0.3 \\
\hline Moreau et al ${ }^{24}$ (2001) & $5,400 \pm 500^{c}$ & $9,700 \pm 400^{c}$ & 4,300 & $81.1 \pm 5.9$ & $79.8 \pm 5.8$ & $-1.3^{b}$ \\
\hline Hultquist et al ${ }^{25}$ (2005) & $5,603 \pm 1,214$ & $10,159 \pm 292^{c}$ & 4,556 & $82.0 \pm 3.1^{c}$ & $81.5 \pm 3.1^{c}$ & -0.5 \\
\hline Chan et $\mathrm{al}^{26}$ (2004) & $7,029 \pm 3,100$ & $10,480 \pm 3,224$ & 3,451 & $79.4 \pm 17.3$ & $77.9^{a}$ & $-1.5^{a, b}$ \\
\hline \multicolumn{7}{|c|}{ NR $=$ not reported in the study report. } \\
\hline \multicolumn{7}{|c|}{$\begin{array}{l}\text { a Calculation was based on other data in the study report. } \\
{ }^{\mathrm{b}} \text { Difference between the preintervention and postintervention values was significant at the } .05 \text { level. } \\
{ }^{c} \text { Means } \pm \text { standard errors. }\end{array}$} \\
\hline
\end{tabular}

\section{Study Characteristics and Results}

Table 1 gives an overview of each of the 9 studies included in the final analysis, with studies listed in ascending order according to the average postintervention step count. Among the 9 cohorts examined, the sample size ranged from 15 to 106 participants, for a total of 307 participants, $73 \%$ of whom were women and $27 \%$ of whom were men. The duration of the intervention ranged from 4 weeks to 1 year, with a median duration of 16 weeks.

Table 2 shows results of the studies. All but 1 of the cohorts examined had a small decrease in weight at the end of the intervention. The range of weight change for the 9 cohorts was +0.30 to $-3.70 \mathrm{~kg}$, with an unadjusted mean weight change across the cohorts of $-1.42 \mathrm{~kg}$. In 5 of the 9 cohorts, the weight change was statistically significant comparing postintervention with preintervention weight at the $P=.05$ level. 


\begin{tabular}{|c|c|c|c|}
\hline $\begin{array}{l}\text { Intervention } \\
\text { Duration }\end{array}$ & Behavioral Counseling & $\begin{array}{l}\text { Goal Setting } \\
\text { in Pedometer } \\
\text { Intervention }\end{array}$ & Step-Count Logging and Reporting \\
\hline 6 months & $\begin{array}{l}\text { Intensive coaching program including } \\
6 \text { individual sessions and a monthly } \\
\text { newsletter }\end{array}$ & $\begin{array}{l}\text { Step-count walking goals cho- } \\
\text { sen by the participant }\end{array}$ & $\begin{array}{l}\text { Time spent walking and step counts were } \\
\text { recorded in a glucose and exercise log }\end{array}$ \\
\hline 8 weeks & $\begin{array}{l}\text { Eight } 75 \text {-minute small group weekly } \\
\text { sessions based on Health Belief Model }\end{array}$ & Assigned progressive step goals & $\begin{array}{l}\text { Walks were scheduled and steps were } \\
\text { recorded on a scheduler/tracker form and } \\
\text { reported to study staff weekly }\end{array}$ \\
\hline 1 year & Not reported & $\begin{array}{l}\text { Increase daily baseline step } \\
\text { count by } 1,000 \text { steps }\end{array}$ & Not reported \\
\hline 36 weeks & $\begin{array}{l}\text { Information sessions every other week } \\
\text { for } 2 \text { months, then once a month }\end{array}$ & $\begin{array}{l}\text { Gradually increase daily step } \\
\text { count to } 10,000 \text { steps/day }\end{array}$ & Steps were recorded daily in an activity log \\
\hline 16 weeks & $\begin{array}{l}\text { Counseling based on self-efficacy and } \\
\text { social support; } 4 \text { weekly group meet- } \\
\text { ings and a program manual }\end{array}$ & $\begin{array}{l}\text { Individualized step-count goal } \\
\text { setting based on exercises in } \\
\text { the manual }\end{array}$ & Steps per day were recorded in a calendar log \\
\hline 8 weeks & $\begin{array}{l}\text { Pedometer and step-count goal } \\
\text { instructions only }\end{array}$ & Accumulate 10,000 steps/day & $\begin{array}{l}\text { Steps and exercise were recorded in an } \\
\text { activity log }\end{array}$ \\
\hline 24 weeks & $\begin{array}{l}\text { Pedometer and step-count goal } \\
\text { instructions only }\end{array}$ & $\begin{array}{l}\text { Step-count goals gradually } \\
\text { increased to a target of } 3 \mathrm{~km} \\
\text { over baseline }\end{array}$ & $\begin{array}{l}\text { Daily step counts were recorded on log } \\
\text { sheets that were collected every } 2 \text { weeks }\end{array}$ \\
\hline 4 weeks & $\begin{array}{l}\text { Pedometer and step-count goal } \\
\text { instructions only }\end{array}$ & 10,000 daily steps & $\begin{array}{l}\text { Step counts were recorded on a pedometer } \\
\text { with a } 7 \text {-day memory and collected weekly }\end{array}$ \\
\hline 12 weeks & $\begin{array}{l}\text { Counseling based on self-efficacy and } \\
\text { social support; } 4 \text { weekly group meetings }\end{array}$ & Individualized goal setting & $\begin{array}{l}\text { Step-count goals and tracking were logged } \\
\text { on a Web site }\end{array}$ \\
\hline
\end{tabular}

Figure 2. Funnel plot test to test for publication bias. No evidence of publication bias was found.

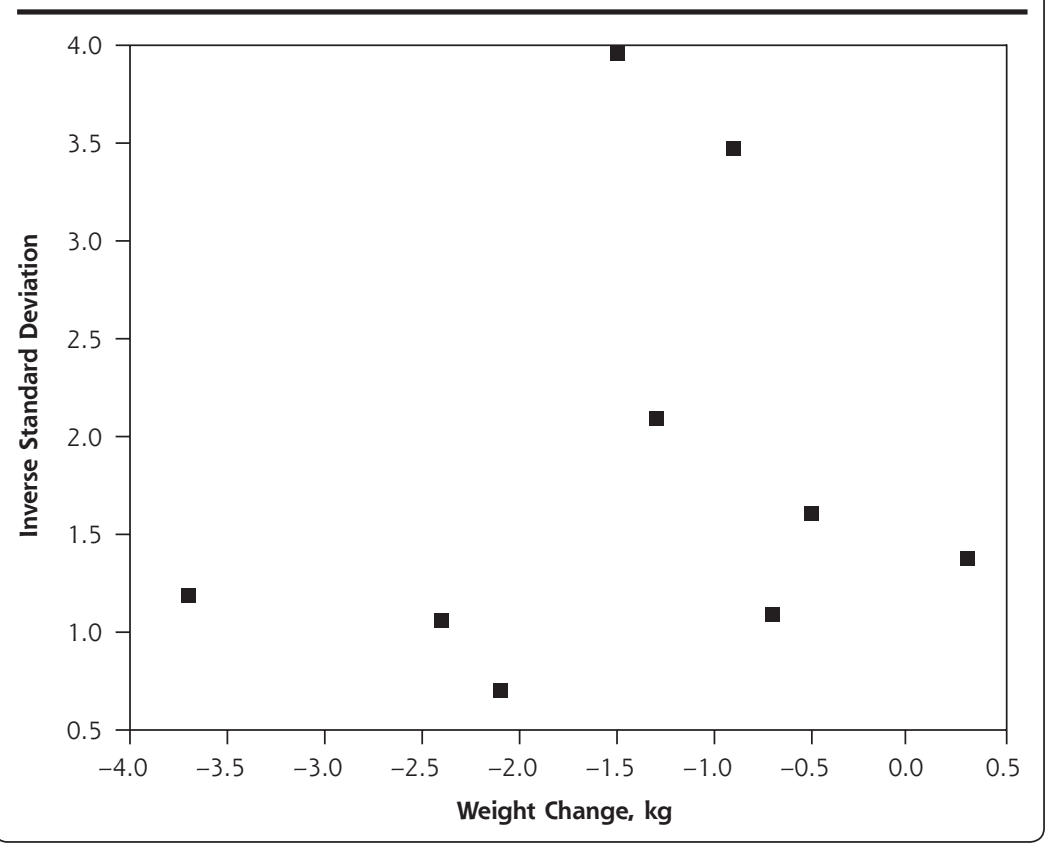

evidence of publication bias. This lack of bias was further confirmed by both the rank-correlation test of Begg and Mazumdar ${ }^{15}(P=.75)$ and the test of Egger et a ${ }^{16}(P=.74)$.

Although these 3 tests are reassuring, they cannot rule out publication bias.

\section{Intervention Effect}

The Cochran Q statistic for testing heterogeneity was 19.16. Based on a $\chi^{2}$ with 8 degrees of freedom, the $Q$ value was statistically significant at the $5 \%$ level $(P=.01)$. We therefore chose to use a random-effects model for our meta-analysis. The pooled estimate of mean weight change from baseline using a random-effects model and combining data from all 9 cohorts was $-1.27 \mathrm{~kg}$ (95\% confidence interval, -1.85 to $-0.70 \mathrm{~kg})$, with an overall intervention effect $(P<.001)$. Figure 3 shows

\section{Publication Bias and Heterogeneity}

Results of the 3 tests to look for evidence of publication bias showed no evidence of such bias. Figure 2 shows the results of a funnel plot, which showed no a forest plot of effect sizes and confidence intervals for all 9 cohorts, again based on the random-effects metaanalysis. The Fisher statistic for the significance of the weight change effect was 87.06 , with $P<.001$. 


\section{Meta-Regression}

We found a strong linear association between the duration of intervention and the magnitude of weight change ( $\beta=-0.05, P=.003)$, with interventions of longer duration being associated with greater weight change. Weight change was not significantly associated with study quality $(P=.08)$.

The scatterplot in Figure 4 shows the strong relationship between intervention duration and weight change. The straight line drawn through the plot is the predicted least squares line based on the meta-regression results with the quality value fixed at 62.8 (the average quality score of the 9 studies).

\section{DISCUSSION}

The average participant in a pedometer-based walking program without dietary change can expect to lose a modest amount of weight, on the order of $1 \mathrm{~kg}$. Results from the 9 cohorts we examined were remarkably consistent and did not vary by the population targeted or the goal-setting strategies used. These findings are consistent with previous research showing that increasing moderate-intensity physical activity tends to result in a modest amount of weight loss. ${ }^{27-30}$

The amount of weight loss attributable to pedom- eter-based walking programs is small but important from a clinical perspective. According to the metaregression results, the average participant adhering to a pedometer-based walking program can expect to lose about $0.05 \mathrm{~kg}$ per week. That translates to a weight loss of about $1 \mathrm{lb}$ every 10 weeks. Over a year, participants can expect to lose about $5 \mathrm{lb}$. Although a $5-\mathrm{lb}$ weight loss for an overweight participant may represent only $2 \%$ to $3 \%$ of that person's body weight, if the participant continues with the pedometer program and if the rate of weight loss is sustained over several years, the target of $7 \%$ of body weight loss used in the Diabetes Prevention Program study ${ }^{4}$ could be achieved.

Such modest amounts of weight loss, no matter how clinically important, may be discouraging to participants whose primary motivation for starting a walking program is to shed pounds. Unrealistic expectations of dramatic weight loss from such a program may result in early dropout. Helping participants set realistic and obtainable goals may be an important part of helping them stick with a walking program. Additionally, encouraging participants who are motivated by weight loss goals to add a dietary component to their walking program may yield more weight loss and thus may increase adherence. ${ }^{10,31,32}$

Average daily step-count increases varied from

Figure 3. Forest plot of effect sizes and $95 \%$ confidence intervals for all 9 cohorts, based on the random effects meta-analysis results.

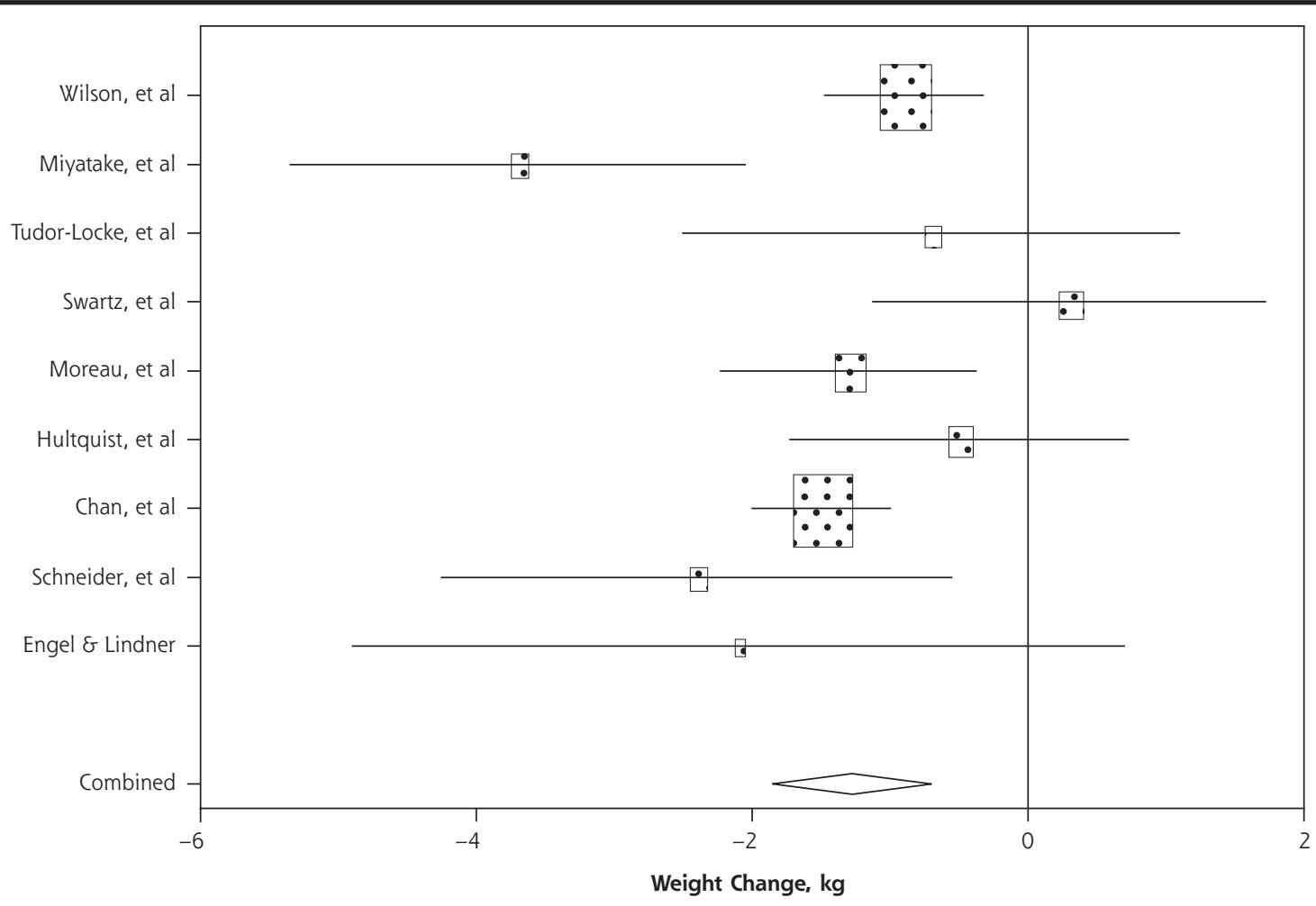

ANNALS OF FAMILY MEDICINE + WWW.ANNFAMMED.ORG + VOL. 6, NO. 1 + JANUARY/FEBRUARY 2008 


\section{Figure 4. Weight change by study intervention duration.}

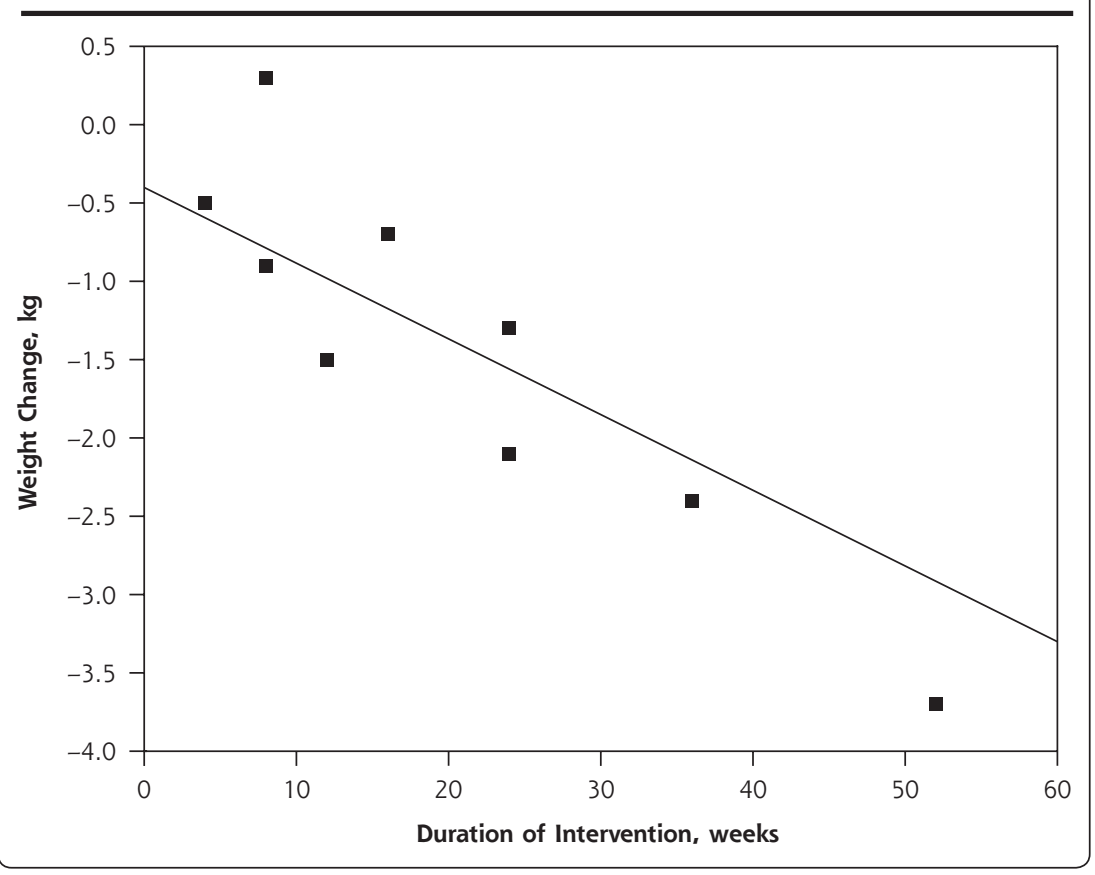

pedometer-based walking intervention. Participants who elect to join a walking program may be particularly motivated to change both their diet and exercise habits. Although none of the study interventions included in the meta-analysis had a dietary component, participants may have decreased their caloric intake on their own; therefore, the real cause of the weight loss might be dietary change rather than increased physical activity. To the extent that the weight loss observed in this review is attributable to participants' selfinitiated diet changes, we would be overestimating the impact of the increased energy expenditure due to the pedometer-based walking program on weight loss. It would not take much of a change in dietary intake to cause

slightly less than 2,000 steps per day to more than 4,000 steps per day across these studies. For the average person, a 2,000-step walk is approximately equal to a 1 -mile walk. ${ }^{33}$ The daily increase in physical activity above baseline thus varied across these studies from an increase of 1 mile to slightly more than 2 miles of walking. At an average pace of 3 miles per hour, that represents an additional 20 to 40 minutes of walking a day and is in the range recommended by national guidelines. ${ }^{34}$ This increase in physical activity can be expected to result in health benefits that are independent of weight loss. Increasing physical activity reduces the risk of adverse cardiovascular events, ${ }^{31,35-38}$ lowers blood pressure, ${ }^{23}$ and helps dieters maintain lean muscle tissue during diet-induced weight loss. ${ }^{39}$ Additionally, a pedometer-based walking program can improve glucose tolerance in people with impaired glucose tolerance or type 2 diabetes. ${ }^{23,40}$

Unfortunately, we know very little about the longterm sustainability of weight loss from pedometerbased walking programs. More long-term studies of such programs are needed to better delineate their weight loss outcomes in that time frame.

There are several important limitations to this study. Because the analysis was based on preintervention-postintervention comparisons rather than on a comparison between randomized groups, there are a number of potential threats to validity, and the pooled estimate of approximately a $1.30-\mathrm{kg}$ weight loss may either overestimate or underestimate the effect of the a 1 -kg weight loss. Only a study in which meticulous records of dietary intake are kept for all participants could ensure that the weight loss we observed was not due to changes in diet. Evidence supporting the theory that walking programs can result in weight loss includes the results of 1 study that examined preintervention and postintervention strength and fitness levels. ${ }^{20}$ This study showed improved cardiorespiratory fitness and leg strength in addition to weight loss, suggesting that the exercise was of sufficient intensity to have a training effect.

It is more likely, however, that we have underestimated the impact of a pedometer-based walking program on weight loss. To the extent that individuals who did not start a walking program would have continued to slowly gain weight rather than maintain a stable weight, our weight loss estimate is lower than the actual change in weight attributable to the walking program. A large randomized controlled trial with a no-walking-program control arm for comparison would allow us to measure both the decreased weight gain and the weight lost from the walking program. The findings of a dose-response association with interventions that lasted longer resulting in larger amounts of weight loss adds evidence to our conclusion that the weight loss detected in this meta-analysis was in fact caused by the intervention itself.

In this study, we pooled the results from 9 cohorts of overweight or obese and sedentary individuals, all of whom participated in a pedometer-based walking 
program. All of the studies included in this meta-analysis were published since 2001, and most are preliminary investigations with small numbers of participants. As we learn more about pedometer-based walking programs and how to study them, both the quality of individual studies and the robustness of meta-analytic results will improve.

In conclusion, pedometer-based walking programs without a dietary intervention component do result in a modest amount of weight loss. Pedometer-based walking programs also do increase step counts and thus can be expected to confer health benefits that are associated with both a modest decrease in weight and an increase in physical activity.

To read or post commentaries in response to this article, see it online at http://www.annfammed.org/cgi/content/full/6/1/69.

Key words: Pedometer; obesity; overweight; weight loss; physical activity; walking; exercise

Submitted February 21, 2007; submitted, revised, June 22, 2007; accepted August 7, 2007.

Preliminary data on the meta-analysis were presented as a poster at the American College of Sports Medicine 2006 Annual Meeting in Denver, Colorado, on June 3, 2006. The abstract was published in Medicine and Science in Sports and Exercise in 2006, volume 38, page S120.

Funding support: A grant from the National Institutes of Health (K23 HL075098) provided funding for this study. The University of Michigan Medical School Student Biomedical Research Program (SBRP) supported Tiffany Newton's time.

\section{References}

1. Department of Health and Human Services, Centers for Disease Control and Prevention. Overweight and Obesity: Obesity Trends: U.S. Obesity Trends 1985-2004. http://www.cdc.gov/nccdphp/ dnpa/obesity/trend/maps/. Accessed: December 14, 2007.

2. Mokdad AH, Ford ES, Bowman BA, et al. Prevalence of obesity, diabetes, and obesity-related health risk factors, 2001. JAMA. 2003;289(1):76-79.

3. Boyle JP, Honeycutt AA, Narayan KM, et al. Projection of diabetes burden through 2050: impact of changing demography and disease prevalence in the U.S. Diabetes Care. 2001;24(11):1936-1940.

4. Knowler WC, Barrett-Connor E, Fowler SE, et al. Reduction in the incidence of type 2 diabetes with lifestyle intervention or metformin. N Engl J Med. 2002;346(6):393-403.

5. Hornbuckle LM, Bassett DR Jr, Thompson DL. Pedometer-determined walking and body composition variables in African-American women. Med Sci Sports Exerc. 2005;37(6):1069-1074.

6. Wyatt HR, Peters JC, Reed GW, Barry M, Hill JO. A Colorado statewide survey of walking and its relation to excessive weight. Med Sci Sports Exerc. 2005;37(5):724-730.

7. Tudor-Locke C, Ham SA, Macera CA, et al. Descriptive epidemiology of pedometer-determined physical activity. Med Sci Sports Exerc. 2004;36(9):1567-1573.

8. Krumm EM, Dessieux OL, Andrews P, Thompson DL. The relationship between daily steps and body composition in postmenopausal women. J Womens Health (Larchmt). 2006;15(2):202-210.
9. Thompson DL, Rakow J, Perdue SM. Relationship between accumulated walking and body composition in middle-aged women. Med Sci Sports Exerc. 2004;36(5):911-914.

10. Yamanouchi K, Shinozaki T, Chikada K, et al. Daily walking combined with diet therapy is a useful means for obese NIDDM patients not only to reduce body weight but also to improve insulin sensitivity. Diabetes Care. 1995;18(6):775-778.

11. Blair SN. Evidence for success of exercise in weight loss and control Ann Intern Med. 1993;119(7 Pt 2):702-706.

12. Downs SH, Black N. The feasibility of creating a checklist for the assessment of the methodological quality both of randomised and non-randomised studies of health care interventions. J Epidemiol Community Health. 1998;52(6):377-384.

13. Follmann D, Elliott $P$, Suh I, Cutler J. Variance imputation for overviews of clinical trials with continuous response. J Clin Epidemiol. 1992;45(7):769-773.

14. Light R, Pillemar D. Summing Up: The Science of Reviewing Research. Cambridge, MA: Harvard University Press; 2005.

15. Begg CB, Mazumdar M. Operating characteristics of a rank correlation test for publication bias. Biometrics. 1994;50(4):1088-1101.

16. Egger M, Davey Smith G, Schneider M, Minder C. Bias in metaanalysis detected by a simple, graphical test. BMJ. 1997;315(7109): 629-634.

17. Cochran W. The combination of estimates from different experiments. Biometrics. 1954;10(1):101-129.

18. Engel $L$, Lindner $H$. Impact of using a pedometer on time spent walking in older adults with type 2 diabetes. Diabetes Educ. 2006;32(1):98-107.

19. Wilson DB, Porter JS, Parker G, Kilpatrick J. Anthropometric changes using a walking intervention in African American breast cancer survivors: a pilot study. Prev Chronic Dis. 2005;2(2):A16.

20. Miyatake N, Nishikawa $H$, Morishita A, et al. Daily walking reduces visceral adipose tissue areas and improves insulin resistance in Japanese obese subjects. Diabetes Res Clin Pract. 2002;58(2):101-107.

21. Schneider PL, Bassett DR Jr, Thompson DL, Pronk NP, Bielak KM. Effects of a 10,000 steps per day goal in overweight adults. Am J Health Promot. 2006;21(2):85-89.

22. Tudor-Locke C, Bell RC, Myers AM, et al. Controlled outcome evaluation of the First Step Program: a daily physical activity intervention for individuals with type II diabetes. Int J Obes Relat Metab Disord. 2004;28(1):113-119.

23. Swartz AM, Strath SJ, Bassett DR, et al. Increasing daily walking improves glucose tolerance in overweight women. Prev Med. 2003;37(4):356-362.

24. Moreau KL, Degarmo R, Langley J, et al. Increasing daily walking lowers blood pressure in postmenopausal women. Med Sci Sports Exerc. 2001;33(11):1825-1831.

25. Hultquist CN, Albright C, Thompson DL. Comparison of walking recommendations in previously inactive women. Med Sci Sports Exerc. 2005;37(4):676-683.

26. Chan CB, Ryan DA, Tudor-Locke C. Health benefits of a pedometerbased physical activity intervention in sedentary workers. Prev Med. 2004;39(6):1215-1222.

27. King AC, Tribble DL. The role of exercise in weight regulation in nonathletes. Sports Med. 1991;11(5):331-349.

28. Slentz CA, Duscha BD, Johnson JL, et al. Effects of the amount of exercise on body weight, body composition, and measures of central obesity: STRRIDE-a randomized controlled study. Arch Intern Med. 2004;164(1):31-39.

29. Votruba SB, Horvitz MA, Schoeller DA. The role of exercise in the treatment of obesity. Nutrition. 2000;16(3):179-188.

30. Littman AJ, Kristal AR, White E. Effects of physical activity intensity, frequency, and activity type on 10-y weight change in middle-aged men and women. Int J Obes (Lond). 2005;29(5):524-533. 
31. Jensen $G L$, Roy MA, Buchanan AE, Berg MB. Weight loss intervention for obese older women: improvements in performance and function. Obes Res. 2004;12(1):1814-1820.

32. Richardson CR, Brown BB, Foley S, Dial KS, Lowery JC. Feasibility of adding enhanced pedometer feedback to nutritional counseling for weight loss. J Med Internet Res. 2005;7(5):e56.

33. Bassett DR, Strath SJ. Use of pedometers to assess physical activity. In: Welk GJ, ed. Physical Activity Assessments for Health-Related Research. Champaign, IL: Human Kinetics; 2002:163-177.

34. US Department of Health and Human Services. Physical Activity and Health: A Report of the Surgeon General. Atlanta, GA: Centers for Disease Control and Prevention, National Center for Chronic Disease Prevention and Health Promotion; 1996.

35. Manson JE, Hu FB, Rich-Edwards JW, et al. A prospective study of walking as compared with vigorous exercise in the prevention of coronary heart disease in women. N Engl J Med. 1999;341(9):650-658.
36. Swain DP, Franklin BA. Is there a threshold intensity for aerobic training in cardiac patients? Med Sci Sports Exerc. 2002;34(7):1071-1075.

37. Hamdorf PA, Penhall RK. Walking with its training effects on the fitness and activity patterns of 79-91 year old females. Aust N Z J Med. 1999;29(1):22-28.

38. Duncan GE, Anton SD, Sydeman SJ, et al. Prescribing exercise at varied levels of intensity and frequency: a randomized trial. Arch Intern Med. 2005;165(20):2362-2369.

39. Stiegler $P$, Cunliffe $A$. The role of diet and exercise for the maintenance of fat-free mass and resting metabolic rate during weight loss. Sports Med. 2006;36(3):239-262.

40. Houmard JA, Tanner CJ, Slentz CA, Duscha BD, McCartney JS, Kraus WE. Effect of the volume and intensity of exercise training on insulin sensitivity. J Appl Physiol. 2004;96(1):101-106.

\section{CHANCE-OF-ADDRESS FORM FAMILY MEDICINE}

Please complete this form and mail to the following address or fax to Annals Circulation at 913-906-6080:

Annals of Family Medicine, Circulation Department, 11400 Tomahawk Creek Pkwy, Leawood, KS 66211-2680

Check if member of sponsoring organization:

$\square$ AAFP $\square$ ABFM $\square$ STFM $\square$ ADFM
$\square$ AFMRD $\square$ NAPCRG $\square$ CFPC

ID number from label on your journal cover

OLD Information (Please print.)

Name

Company (if applicable)

Address (Street plus Apt or Ste)

\begin{tabular}{ll}
\hline City & State \\
\hline Country & Postal Code (9-digit ZIP for US) \\
\hline Telephone & Fax \\
\hline E-Mail &
\end{tabular}

NEW Information (Please print.)

\begin{tabular}{ll}
\hline Name \\
\hline Company (if applicable) \\
\hline Address (Street plus Apt or Ste) \\
\hline City \\
\hline Country \\
\hline Telephone \\
\hline E-Mail
\end{tabular}

